\title{
Aproximações possíveis entre os estudos da deficiência $e$ as teorias feministas e de gênero
}

\author{
Molise de Bem Magnabosco' \\ 0000-0002-0388-269X \\ Leonardo Lemos de Souza' \\ 0000-0002-3331-1847
}

'Universidade Estadual Paulista, Programa de Pós-Graduação em Psicologia, Assis, SP,

Brasil.19806-900-posgradu.assis@unesp.br

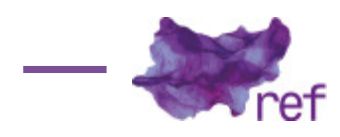

Resumo: Os estudos feministas e de gênero e aqueles sobre as deficiências constituem, tradicionalmente, campos separados de pesquisa e teorização, tendo cada um objetos e âmbitos distintos e bem definidos. Na década de 1990, tais perspectivas foram problematizadas por mulheres com deficiências pesquisadoras das teorias feministas, que apontaram tanto as limitações de ambos os campos quanto a necessidade de articulá-los para constituir perspectivas mais complexas de compreensão da sociedade como um todo. Nesse sentido, este trabalho busca estabelecer tais articulações, pensando o campo das deficiências a partir dos estudos feministas e de gênero, em uma perspectiva queer/crip de interrogação da sociedade com vistas à constituição de um mundo aleijado. Palavras-chave: Deficiência; Modelo social da deficiência; Epistemes feministas; Teoria crip.

Possibles Approximations between Disability Studies and Feminist and Gender Theories Abstract: Feminist and gender studies and those about disabilities are traditionally separate fields of research and theorizing, and each one have distinct and well defined objects and scopes. Such approaches were questioned in the 1990s by women with disabilities who were also feminist theories researchers, pointing to the limitations of both fields and the need to articulate them in order to form more complex perspectives of understanding the society as a whole. In this sense, this study intends to establish such articulations, thinking the field of disabilities as of the feminist and gender studies, in a queer/crip perspective that questions society and aims to set up a crippled world.

Keywords: Disability; Social Model of Disability; Feminist Epistemology; Crip Theory.

\section{Introdução}

A relação que a sociedade estabelece com as pessoas com deficiências se constitui historicamente como desafio, variando desde a exclusão desses sujeitos do convívio social, internando-os em hospitais psiquiátricos, no século XVI, até a sua inserção nos diversos espaços sociais possibilitada pela realização de adaptações com vistas à superação das barreiras interpostas. Os paradigmas referentes a tal processo têm sido modificados, bem como progrediu a inserção das pessoas com deficiências na sociedade.

Tais paradigmas refletem os contextos sociais e históricos em que são desenvolvidos, referentes inclusive às formas como se articulam os campos de estudos e os movimentos sociais. As discussões sobre as deficiências foram, tradicionalmente, realizadas dentro dos estudos sobre as deficiências (disability studies), acompanhadas pela constituição de movimentos de sua afirmação como identidade política. Na década de 1990, mulheres com deficiência, pesquisadoras das teorias feministas - como Jeanny Morris (1993) e Margaret Lloyd (1992) -, questionaram os campos do feminismo e das deficiências e destacaram os equívocos decorrentes de leituras que não intersectassem as duas áreas. Tal debate resultou nos estudos feministas sobre as deficiências (feminist disability studies). 
Mesmo não sendo recentes, tais discussões ainda apresentam-se timidamente, podendo contribuir para problematizar o olhar que temos sobre as deficiências e para enriquecer as discussões sobre a inclusão das pessoas com deficiências na sociedade. Por isso, buscamos desenvolver, neste ensaio, articulações possíveis entre os estudos da deficiência e as teorias feministas e de gênero.

\section{Encontro(s) dos estudos feministas e de gênero com os da deficiência: delineando novas perspectivas articuladoras}

O paradigma da inclusão, que atualmente assegura o direito das pessoas com deficiência de conviverem em sociedade, fundamenta-se no modelo social da deficiência, segundo o qual a deficiência não é responsável pelas desvantagens vivenciadas pelo sujeito que a possui, mas sim a sociedade, que não se ajusta à diversidade existente na população e, por isso, apresenta barreiras que revelam a visão normalizadora e o preconceito vigentes, impedindo o desenvolvimento dos sujeitos com deficiência, bem como a sua inserção nos variados contextos (Luciana BAMPI; Dirce GUILHEM; Elioenai ALVES, 2010). A proposta desse modelo é modificar as estruturas que provocam ou reforçam a deficiência, mais que tratar as lesões decorrentes dela. Quando comparado a modelos anteriores (como o modelo médico'), há uma diferenciação tanto na lógica de causalidade da deficiência - que passa do indivíduo para a estrutura social quanto no seu conceito - ao considerar a deficiência como sendo uma variação humana e não mais compreendida como uma forma de vida inferior às demais (Débora DINIZ, 2003, 2007; Rosemarie GARLAND THOMSON, 2005).

Débora Diniz (2003; 2007) afirma que esse modelo, difundido na década de 1970, apresentava premissas fundamentadas nos estudos de gênero e feministas, pois se opunha ao mecanismo de opressão das pessoas com deficiência e considerava imoral a desigualdade estabelecida. Ao problematizar a desessencialização da desigualdade, deslocou o significado da deficiência das lesões para o contexto social, como fizeram as teorias de gênero ao separarem o sexo, pensado a partir do corpo biológico, do gênero, compreendido como construção histórica e social. A desigualdade passou a ser vista como imposta pelas barreiras sociais, principalmente arquitetônicas e de transporte, lógicas estabelecidas por um sistema capitalista de produção. Quando fossem eliminadas, seria possível, às pessoas com deficiências, ter independência valor ético fundamental do modelo social da deficiência - e ser tão produtivas quanto quaisquer outros sujeitos. Conforme a antropóloga brasileira, tal modelo, inicialmente proposto por homens com lesão medular, não estabeleceu uma crítica mais profunda do sistema de produção que regulava a vida no trabalho.

O fato de os primeiros teóricos do modelo social serem homens com deficiência, brancos e membros da elite, conforme Diniz (2003), não politizou a questão, posto que restringiu à vida pessoal queixas relativas às dores e exigências desse corpo que deveria ser produtivo. A esfera do cuidado não foi considerada e tal proposta ignorou aqueles sujeitos com deficiência que, independentemente dos ajustes sociais realizados, não conseguiriam ser inseridos no mercado de trabalho de forma autônoma devido à extensão das suas limitações. Tais críticas feitas pelas teóricas feministas (mulheres com deficiência ou cuidadoras de pessoas com deficiência), na década de 1990, possibilitaram a reformulação do modelo social da deficiência, que passou a ser pensado em sua segunda geração. Essa nova proposta assumiu o cuidado como princípio ético e a igualdade pela interdependência como um princípio de justiça mais adequado nos estudos sobre a deficiência.

Tal atualização conceitual refletiu a crítica que os estudos feministas fizeram à ciência moderna, androcêntrica, por fundamentar-se na racionalidade, objetividade e neutralidade (Cecília SARDENBERG, 2007). O sujeito iluminista era o homem branco ocidental, assim como o sujeito da primeira formulação do modelo social da deficiência era o homem com deficiência, branco e membro da elite. Segundo Cecília Sardenberg (2007), tal androcentrismo trouxe prejuízos para as mulheres, historicamente consideradas inferiores aos homens, bem como ocultou as relações de poder entre os sexos, contribuindo para reforçar tanto as hierarquias de gênero quanto as demais hierarquias sociais. Nesse sentido, Teresa de Lauretis (1994) afirma que teorias também são tecnologias de gênero: produzem, disseminam e instalam representações de gênero, o que revela a necessidade de se avaliar criticamente os modelos teóricos vigentes.

O rompimento com essas hierarquias possibilitou a constituição de outra perspectiva de ciência, guiada pelos saberes localizados. Tal concepção, proposta por Donna Haraway (1995), busca a objetividade, mas pensada como localmente contextualizada, limitada e parcial. Trata-

\footnotetext{
${ }^{1}$ Ao designar o modelo médico como anterior ao social, referimo-nos ao tempo de sua difusão como fundamento para propostas referentes à participação da pessoa com deficiência na sociedade (como a integração). Não dizemos, com isso, que ele está superado. Ao contrário, acreditamos que muitas das representações referentes às pessoas com deficiência na atualidade ainda têm como base esse entendimento.
} 
se de uma ciência produzida a partir de um lugar situado, crítico, muitas vezes constituído pela perspectiva dos sujeitos subjugados, e que "parecem prometer explicações mais adequadas, firmes, objetivas, transformadoras do mundo" (HARAWAY, 1995, p. 23).

Uma perspectiva científica não se revela feminista apenas por abordar questões referente às mulheres, mas por ter um projeto de ciência eminentemente intervencionista, comprometido com a diversidade, com vistas à promoção da equidade e à mudança dos paradigmas vigentes, em busca de uma sociedade mais igualitária (Sofia NEVES; Conceição NOGUEIRA, 2005). João Oliveira (2010) afirma que os saberes feministas são intersticiais, dialógicos, constituídos pela dissolução das fronteiras que demarcam campos do conhecimento. O feminismo é uma "prática de interrogação do mundo" (OLIVEIRA, 2010, p. 33) e, portanto, base importante para problematizar inclusive as teorizações sobre as deficiências.

\section{Fraturando identidades sólidas: a fluidez de fronteiras e a hibridização como componentes para pensar a deficiência}

Além das problematizações apresentadas anteriormente, os estudos feministas também inseriram o prisma do gênero no campo das deficiências, pois as teóricas feministas denunciaram que ser mulher e ter deficiência, ou cuidar de alguém com deficiência, constituía uma experiência muito diferente da tida pelos homens com deficiência, pois havia, no primeiro caso, confluência de fatores de desigualdade ${ }^{2}$. Essa confluência sinaliza a existência de diferentes categorias de opressão, que se interligam e se constituem mutuamente, caracterizada pelos estudos feministas como interseccionalidade (Patrícia H. COLLINS; Sirma BILGE, 2016).

O gênero se relaciona com outras categorias, como raça/etnia, idade e classe social, que se entrecruzam na constituição da identidade, fazendo-a singular e culminando no fato de que "se alguém 'é' uma mulher, isso certamente não é tudo o que esse alguém é" (Judith BUTLER, 2015, p. 21). Há, portanto, a vivência de uma identidade única, distinta da simples soma das categorias consideradas individualmente. Esse processo foi também denominado por Rosi Braidotti (2002) como constituinte de uma subjetividade nômade, que recusa o senso de identidade fixa, demarcada. As identidades políticas totalizantes foram fraturadas e substituídas por uma compreensão situada dos sujeitos (BRAIDOTTI, 2002; HARAWAY, 2009).

Tal discussão traz a necessidade de se abordar, também, outras categorias, como a deficiência. Rosemarie Garland Thomson (2005) indica que os estudos feministas frequentemente tratam dos modos como gênero se inter-relaciona com raça, etnia, sexualidade e sistema de classes, mas pouco discutem sua articulação com as deficiências - importante elemento de análise para se pensar a complexidade da formação da identidade (GARLAND THOMSON, 2005; Alison KAFER, 2013). Igualmente, Jeanny Morris (1993, p. 55) denunciou "the failure of feminism to integrate the concerns of disabled women into its theory, methodology, research and politics" ${ }^{3}$, sendo tal falha centrada na invisibilidade da temática das deficiências nas agendas feministas e na objetificação dos sujeitos com deficiência, quando ela é abordada. Isso culmina em práticas feministas baseadas em preceitos liberais, que enfraquecem a luta ao buscar o empoderamento das mulheres em geral, a partir de valores como autonomia e independência (GARLAND-THOMSON, 2001).

Articulando os dois campos, Garland-Thomson (2002) aponta paralelos comuns entre as representações historicamente atribuídas aos corpos femininos e aos com deficiência: ambos são considerados desviantes ou inferiores, restritos ao âmbito da vida privada e definidos em oposição a uma norma (homens ou pessoas sem deficiência) naturalizada como fisicamente superior. A autora propõe a confluência dessas áreas, constituindo o que chamou de teoria feminista da deficiência (feminist disabity theory), importante para todos, considerando que a deficiência é a mais humana das experiências: se vivermos tempo o suficiente, todos nós a teremos - ideia também apresentada pela Organização Mundial de Saúde (2012) - posto que dificuldades na funcionalidade do nosso corpo advêm do envelhecimento.

Segundo essa perspectiva, a deficiência é uma narrativa culturalmente fabricada, produzindo subjetividades através da diferenciação dos corpos. Tem como maior desafio realizar crítica sobre gênero e deficiência como sistemas de opressão exclusivamente interligados, a partir dos quais todos os sujeitos são avaliados, com implicações políticas. Essa narrativa compõe um sistema de classificação que agrupa aqueles que fogem dos padrões socialmente estabelecidos, validando os privilégios atribuídos aos sujeitos que se enquadram nesses modelos. Em suma, abordar deficiência é discutir relações de poder (GARLAND-THOMSON, 2001; 2002).

\footnotetext{
2 Tanto a variação da experiência da deficiência, em um nível individual, como sua prevalência e extensão, considerando fatores epidemiológicos, são, também, marcadas por outros fatores, além do gênero, como classe social e ambiente (Organização Mundial de Saúde, 2012) - o que revela a necessidade de adotarmos uma perspectiva interseccional em sua consideração.

3 "o fracasso do feminismo em integrar as preocupações das mulheres com deficiência em sua teoria, metodologia, pesquisa e política" (tradução nossa).
} 
Tal relação é discutida, também, por Judith Butler $(2000,2015)$, que propôs o conceito da abjeção para se referir aos corpos que fogem da regulação binária do sexo e da heterossexualidade, sendo, por isso, repelidos. Butler também caracteriza como abjetos todos os corpos ininteligíveis dentro do processo discursivo de construção das identidades, "cujas vidas não são consideradas 'vidas' e cuja materialidade é entendida como 'não importante'" (Baukje PRINS; Irene MEIJER, 2002, p. 161). Submetidos a um processo de expulsão e estranhamento, passam a configurar o "não eu", o "Outro" (todos aqueles que são diferentes das identidades culturalmente hegemônicas), não sendo considerados sujeitos. A partir da diferenciação relativa a esses corpos, a caracterização dos sujeitos é estabelecida como sendo aquele que não é abjeto. Definimos quem somos não apenas pelo reconhecimento das semelhanças que temos com algumas pessoas, como também pela distinção de outras, negando suas características.

Os corpos com deficiência são, portanto, corpos abjetos, dos quais é retirada a humanidade. São, pois, excluídos socialmente, sendo uma forma de controle (OLIVEIRA, 2010). Assim:

A abjeção ou repulsa que o corpo deficiente provoca nos "normais" afeta a relação com o outro e com o próprio corpo naquele que se sente diferente, [...] que se soma à exigência de encaixar o outro dentro de padrões hegemônicos antropométricos, fisiométricos e psicométricos, sendo ele exterminado ou segregado, apartado do convívio com os "perfeitos, belos e saudáveis" (Anahi MELLO; Adriano NUERNBERG, 2012, p. 644).

Contrapondo-se a isso, Haraway (2009) trata da fratura das identidades sólidas, plenamente delimitadas, estabelecendo a fluidez das fronteiras identitárias. Para ela, os sujeitos são complexos híbridos, ciborgues, formados por opostos: natureza e cultura, organismo e máquina. São, pois, tanto natural quanto artificialmente constituídos - ideia esta que fluidifica os dualismos, os quais afastam e subjugam aqueles considerados outros (HARAWAY, 2009; Donna REEVE, 2012). Haraway (2009) propõe a união por coalisões mais do que por diferenças, bem como prega a afinidade como valor, para além da identidade.

A relação com a tecnologia faz dos artefatos tecnológicos extensões ou composições dos corpos dos sujeitos (Hari KUNZRU, 2009). Essa lógica também é válida para as pessoas com deficiência, que necessitam de adaptações, órteses e/ou próteses nas diversas atividades que realizam, de vida diária e social ou referentes ao trabalho. Nesse sentido, Haraway (2009, p. 92) afirmou: "talvez os paraplégicos e outras pessoas seriamente afetadas possam ter (e algumas vezes têm) as experiências mais intensas de uma complexa hibridização com outros dispositivos de comunicação".

Nessa perspectiva, Reeve (2012) explicita as contribuições da teoria ciborgue para os estudos sobre as deficiências, apontando autores que discutem a limitação para tal colaboração, dado o contexto social estabelecido. Grande parte da população com deficiência também apresenta baixa renda - segundo dados da Organização Mundial de Saúde (2012), pessoas com deficiência têm maiores chances de serem pobres do que aquelas que não a têm, principalmente nos países desenvolvidos -, o que limita seu acesso a tais recursos, uma vez que possuem um custo elevado. Por isso, se há investimentos em tecnologia para criar novas adaptações, essas melhorias não necessariamente alcançam quem delas precisa e, consequentemente, não possibilitam melhoria da qualidade de vida das pessoas com deficiências.

O direito de os sujeitos se hibridizarem é economicamente determinado, vinculado a aspectos como gênero, classe e etnia. Ignorar esses fatores torna a transgressão de limites proposta pela teoria inexequível, desconsidera a materialidade da deficiência, as práticas sociais e culturais que sustentam a experiência da exclusão sofrida pelas pessoas com deficiências (REEVE, 2012).

Há, também, poucas discussões referentes às implicações culturais e sociais do uso das próteses, bem como da experiência vivenciada pelos sujeitos protetizados. Tal destaque adquire relevância, pois a tecnologia reestabelece as funcionalidades afetadas pela deficiência, sendo historicamente associada à normalização, à reabilitação e à cura. Esse modelo pode contribuir para reforçar uma visão individualizante da deficiência, o que perpetua o estigma dos corpos ciborgues, considerados incompletos (CAMPBELL, 2009 apud REEVE, 2012).

Tal entendimento é compartilhado por Alison Kafer (2013), ao questionar o uso da pessoa com deficiência apenas como exemplo autoevidente do ciborgue, sem ponderação no que diz respeito às consequências da interação entre ela e a tecnologia - por exemplo, seu uso pode acarretar dor e desconforto, além de haver pessoas com deficiências que não se adaptam aos recursos tecnológicos ou que nem desejam utilizá-los. Tanto a deficiência em si quanto tais sujeitos são, então, descontextualizados, despolitizados e reduzidos à passividade - panorama que revela ser necessário ter cautela, pois o uso da figura ciborgue, ao contrário do que Haraway propôs, pode acentuar os binarismos, no lugar de romper fronteiras. Desse modo, Kafer (2013, p. 105-106) reconhece o potencial transformador do ciborgue para as discussões sobre as deficiências: 
The cyborg figure certainly holds much promise for a disability politics; from its suspicion of essentialist identities to its insistence on coalition work to its interrogation of ideologies of wholeness, the cyborg offers productive insights for developing a feminist disability vision of the future ${ }^{4}$.

Um futuro que comporte perspectivas para além da cura e da reabilitação. Para que a figura do ciborgue seja referencial, a partir da crítica feminista, Kafer (2013) afirma ser necessário aleijá-la: deve considerar as diversas relações possíveis entre pessoas e tecnologia, que envolvem a restrição ao acesso, as dores e incômodos consequentes e, inclusive, a possibilidade de opção pelo não uso de um recurso que visa à normalização. Trata-se de se opor às fáceis celebrações dos consertos tecnológicos, buscando estabelecer uma relação mais complexa entre recurso e sujeito.

A compreensão do ciborgue pode ainda promover a fluidificação de fronteiras entre o sujeito e outros corpos, como os dos animais (como cães-guia) ou de outras pessoas - cuidadoras das pessoas com deficiências ou outras que as auxiliem. Promovem e possibilitam, portanto, segundo Kafer (2013), relações de interdependência que geram novas formas de estar no mundo - ou seja, novas subjetividades.

Contudo, o aleijamento da perspectiva ciborgue acontece por meio de práticas políticas de transformação social. "Cripping the cyborg [...] means recognizing that our bodies are not separate from our political practices; neither assistive technologies nor our uses of them are ahistorical or apolitical"5 (KAFER, 2013, p. 120) - o que revela o compromisso com o reconhecimento do protagonismo e dos usos políticos das corporificações dissidentes no questionamento das práticas capacitistas (isto é, de discriminação em função da deficiência) socialmente disseminadas.

A teoria ciborgue revela-se, pois, um importante recurso teórico por propor a dissolução das barreiras e ruptura dos dualismos. Isto posto, um caminho alternativo é sugerido por Rosi Braidotti $(2010,2015)$ ao trazer o homem para uma rede de relações na qual deixa de ser o centro e modelo e passa a compor com os demais elementos do mundo a partir da igualdade de status. A filósofa feminista rompe com o ideal humanista e com o dualismo, fundantes do conceito de identidade, resultando no abandono da ideia de identidade fixa e estável para o sujeito, bem como da lógica binária que dissocia eu-outro - e que tem como consequência a redução da diferença à pejoração, à desqualificação e à exclusão.

Como alternativa, a autora reafirma a subjetividade baseada em uma profunda inter-relação entre nós e o mundo, nomeada pós-humana, que é relacional, rizomática, nômade e conecta o homem a outros humanos, a não-humanos e ao meio-ambiente, fundindo-nos ao ambiente tecnologicamente modificado. Tal modificação, fundamentada na supremacia das relações e na interdependência entre todos, assenta-se na valorização das múltiplas possibilidades de existência, buscando reavivar o que são capazes de fazer os corpos, sejam eles quais forem.

Nesse sentido, Griet Roets e Rosi Braidotti (2012) abordam as contribuições da subjetividade nômade para os estudos críticos sobre a deficiência a partir da visão de um sujeito social, corporificado e não-dualista. Essa compreensão considera uma visão não cristalizada do ser humano, que foge de qualquer enquadramento ou determinismo, aberta aos movimentos de transição. As pessoas com deficiências se constituem como sempre em processo, em uma relação com a coletividade caracterizada como limítrofe, em função das diferenças, mas também de composição dos grupos sociais, a partir da interconexão entre todos. Trata-se, portanto, de uma relação de pertencimento, que contribui para valorizar a diversidade na composição dos juízos referentes a quais tipos de vidas humanas são possíveis. Tal perspectiva, para as autoras, expande a nossa compreensão de subjetividade, que é constituída borrando-se os limites entre o sujeito e os outros, e atribui importância às pessoas com deficiência, que trazem à tona a diversidade das possibilidades de existência.

\section{Em busca de um planeta aleijado: a deficiência compreendida a partir da Teoria Crip}

A fluidificação das fronteiras, que resulta em uma flexibilização das definições antes consideradas rígidas e, portanto, no rompimento com a diferenciação entre os sujeitos e aqueles tidos como abjetos, é também preconizada pela Teoria Crip. Proposta por Robert McRuer (2006) a partir dos pressupostos da Teoria Queer - que questiona os mecanismos socioculturais de poder que conformam a sexualidade -, busca compreender "how bodies and disabilities have been conceived and materialized in multiple cultural locations, and how they might be understood and imaged as forms of resistance to cultural homogenization"6 (McRUER, 2006, p. 33).

\footnotetext{
4 "A figura do ciborgue certamente sustenta muita promessa para uma política da deficiência; desde sua desconfiança das identidades essencialistas, até sua insistência nos trabalhos de coalisão e seu questionamento das ideologias de totalidade, o ciborgue oferece compreensões produtivas para o desenvolvimento de uma visão feminista da deficiência sobre o futuro" (tradução nossa).

5 "Aleijar o ciborgue [...] significa reconhecer que nossos corpos não são separados de nossas práticas políticas; nem as tecnologias assistivas, nem nossos usos delas são ahistóricos ou apolíticos" (tradução nossa).

6 "como corpos e deficiências têm sido concebidos e materializados em múltiplas localizações culturais e como podem ser entendidos e imaginados como formas de resistência à homogeneização cultural" (tradução nossa).
} 
Derivado de cripple, que, em inglês, significa aleijado, o termo crip, inicialmente restrito às pessoas com deficiência física, foi expandido e, atualmente, abrange, também, as deficiências sensoriais e intelectual. McRuer (2006) destaca que esse termo é fluido e sujeito a mudanças, pois é requerido por aqueles aos quais não se refere inicialmente - podendo, então, ser pleiteado por pessoas sem deficiência, como um posicionamento políico, de forma semelhante ao uso do termo queer, conforme afirma Richard Miskolci (2016) ${ }^{7}$. A Teoria Crip busca romper com os binarismos, considerando-os não-naturais, cultural e politicamente hierarquizados, de maneira que coaduna com as perspectivas de Braidotti (2015) e Haraway (2009), as quais propõem a compreensão das vidas como relacionais, não-unitárias e pensadas a partir de um enfoque antiessencialista.

De acordo com Haraway (2009), isso possibilita a desnaturalização das identidades, vistas como historicamente construídas a partir do colonialismo, do patriarcado e do capitalismo - eixos aos quais são acrescentados o da heteronormatividade, o da cisgeneridade e o da corponormatividade, propostos, respectivamente, pelas teorias Queer, Transfeministas e Crip. Devemos questionar tais bases, que reforçam a estigmatização e a opressão, explicitando seus mecanismos de penetração e perpetuação sociais, bem como trazer à visibilidade as identidades dissidentes, que não se encaixam nos padrões propagados pelas ideologias hegemônicas.

McRuer (2006) identifica proximidade entre heterossexualidade e corponormatividade, ambas compulsórias em nossa estrutura social e que, portanto, estão relacionadas ao padrão de normalidade, definido em oposição ao que é dissidente - conforme propôs Butler (2015), ao tratar da abjeção. Por isso, ter um corpo capaz (base da corponormatividade) significa não ter deficiência, assim como a heterossexualidade é definida em oposição à homossexualidade.

A caracterização do corpo capaz é, também, situada a partir do potencial para o trabalho: trata-se do corpo apto ao desempenho, submetido aos esforços físicos demandados pelos sistemas de produção - cuja definição tem origem na expansão do capitalismo industrial. Tal historicidade tem sido obliterada, fazendo com que a corponormatividade seja onipresente e assuma contornos de formação disciplinar, tal como aconteceu com a heterossexualidade.

Segundo McRuer (2006), esses padrões fazem da performatividade, proposta por Butler (2015), importante elemento que constitui as hegemonias: a aptidão corporal e a heterossexualidade são repetidamente apontadas como preferência, em detrimento dos corpos com deficiência e homossexuais, sendo estabelecidas como objetivos a serem alcançados.

A partir da atribuição, feita pelo movimento queer, de outros sentidos a termos inicialmente pejorativos, conferindo-lhes potência, McRuer (2006) propõe a ressignificação de outras formas de corporificação possíveis, para além das socialmente valorizadas, sendo tal resistência à norma estabelecida a posição fundamental das teorias Crip e Queer. McRuer (2015) e Kafer (2017) fazem referência o uso do termo crip como verbo (tocrip ou crippin', que poderíamos traduzir para aleijar), atribuindo-Ihe o sentido de questionar, a partir de posições anticapacitistas, as assertivas referentes aos padrões estabelecidos como normalidade, fazendo uma revisão radical desses parâmetros. Para tanto, Kafer (2013, p. 9) afirma que é necessário politizar as discussões sobre as deficiências e, dessa forma, considerar que estão permeadas por "relations of Power and that those relations, their assumptions, and their effects are contested and contestable, open to dissent and debate" ${ }^{\text {. }}$

A autora afirma ainda que a deficiência tem sido despolitizada por ser entendida de forma única, segundo padrões da corponormatividade, reduzida ao viés médico. É, pois, valorada negativamente e considerada um problema a ser erradicado. Ademais, o capacitismo é considerado individualmente, e não como expressão de uma desigualdade estrutural.

Kafer (2013) destaca que tal discordância do modelo médico não faz com que a Teoria Crip se aproprie do modelo social na consideração da deficiência, pois esse paradigma propõe uma cisão entre a lesão (limitação alojada no corpo) e a deficiência (barreiras sociais impostas ao sujeito, gerando sua exclusão). Realiza, portanto, uma ruptura binária entre corpo e relações sociais, na medida em que propõe que é o ambiente no qual o sujeito está inserido que o 'deficientiza', por meio das barreiras sociais e arquitetônicas, estando a lesão, em si, dissociada deste processo, obtendo uma conotação neutra.

A Teoria Crip não nega o peso do ambiente no estabelecimento da deficiência, mas desestabiliza tal divisão ao propor que ambos, lesão e deficiência, são sociais, pois não é possível considerar a lesão separadamente dos significados socialmente atribuídos a ela: "what we understand as impairing conditions - socially, physically, mentally, orotherwise - shift across time and place, and presenting impairment as purely physical obscures the effects of such shifts"' (KAFER, 2013, p. 7).

O modelo social negligencia os impactos que a lesão/deficiência traz para os corpos dos sujeitos por localizar as desvantagens da deficiência nas estruturas sociais que mantêm a

\footnotetext{
${ }_{7}$ Da mesma forma que, para Richard Miskolci (2016), o termo queer é reivindicado por pessoas que estão em relações heterossexuais, condizentes com os padrões sociais, mas que combatem tanto a imposição dessas normas quanto a violência decorrente delas - sujeitos denominados por ele de "hetero-queer".

8 "relações de poder e que essas relações, suas premissas e seus efeitos são contestados e contestáveis, abertos à dissidência e ao debate" (tradução nossa).
} 
desigualdade. Desconsidera, então, aspectos como dor, doenças crônicas e cansaço advindos da deficiência, que impactam os corpos, mas que não são solucionados com adequações arquitetônicas ou atitudinais. Tal inobservância pode trazer como consequência a marginalização das pessoas com deficiência que buscam alternativas que minimizem o seu déficit, além de limitar o estabelecimento de um projeto político da deficiência por ignorar questões importantes de pessoas cujos corpos realmente sofrem (KAFER, 2013; MCRUER, 2015).

Kafer (2013) afirma ainda que a cisão entre corpo e ambiente, entre lesão e deficiência, oculta os modos através dos quais a corponormatividade, por meio da imposição compulsória de um padrão de eficiência e desempenho corporal ou mental, afeta todas as pessoas, inclusive as que não têm deficiências. Por esse motivo, para McRuer (2015), o modelo social da deficiência é mais reformista que revolucionário, bem como a Teoria Crip propõe uma perspectiva culturalmente mais generativa e politicamente radical do que o modelo social.

Igualmente, a Teoria Crip se distingue dos estudos da deficiência por assumir um posicionamento mais radicalmente contestatório e se relacionar com os modelos identitários de modo diferente. Enquanto os estudos da deficiência propõem a centralidade da identidade das pessoas a partir desta característica, a Teoria Crip se revela identitária, pois afirma a deficiência com vistas ao fortalecimento e reconhecimento político da categoria na busca pela ampliação de direitos, mas é, simultaneamente, contra-identitária. Aborda, portanto, as exclusões promovidas por tais movimentos, bem como se recusa a engessar seus limites em definições pré-estabelecidas, por se constituir como uma política de coalisões (KAFER, 2013; MCRUER, 2015, 2016). Neste sentido, McRuer (2015) afirma que a Teoria Crip busca explicitar as conexões com outras formas de sofrimento que não são, inicialmente, vinculadas à deficiência, sem deixar de abordá-la de forma mais específica.

Esse é o primeiro princípio dentre cinco esboçados por McRuer (2006) para a Teoria Crip. Como segundo, temos a reivindicação da perspectiva queer de reconhecer e assumir a condição dissidente - referente à sexualidade ou à deficiência -, de "sair do armário", sendo tal movimento estabelecido através da composição de uma coletividade, em uma ação política. Esse posicionamento difere-se do entendimento de descoberta e anúncio da diferença de forma individualizada, de maneira a rejeitar essa compreensão da deficiência.

O terceiro princípio refere-se à demanda por um outro mundo possível, acessível - tanto em seu sentido mais estrito quanto mais amplo. Estritamente, o termo faz referência à acessibilidade arquitetônica, comunicacional e à eliminação de quaisquer barreiras, inclusive atitudinais, que representem desvantagem para as pessoas com deficiências. Considerá-la globalmente exige o combate ao neoliberalismo e às culturas de redistribuição ascendentes de renda.

A radicalização da ideia de um mundo acessível compõe o quarto princípio: a premissa de que um mundo com deficiência é possível e desejável. Os movimentos que não consideram a deficiência, por meio do silenciamento dos sujeitos ou através da propagação de ideais normalizantes, devem, pois, ser aleijados. Para tanto, é preciso questionar os modos pelos quais as culturas capacitistas e da deficiência, localizadas em esferas públicas ou privadas, são concebidas e materializadas, sendo este o quinto princípio da Teoria Crip.

Tais culturas, que refletem a corponormatividade, trazem consigo a ideia de que uma pessoa sem deficiência é radicalmente autossuficiente, enquanto as que a têm são percebidas como dependentes. Tal pressuposto é combatido por Judith Butler e por Sunaura Taylor durante uma das edições do programa americano Examined Life (Astra TAYLOR, 2009), haja vista que, para elas, todos nós somos dependentes de diferentes estruturas ao longo da vida, bem como uns dos outros. Em um certo momento da entrevista, Sanaura Taylor relata que:

[...] when I did walk, [...] I would be told that I walked like a monkey. And I think that for a lot of disabled people, the violence and the sort of hatred exists a lot in this reminding of people that our bodies are going to age and are going to die. And in some ways I wonder also [...] where our boundaries lie as human and what becomes nonhuman. You know? ${ }^{10}$ (TAYLOR, 2009, p. 205).

Nessa perspectiva é que se insere a necessidade do estabelecimento de uma subjetividade pós-humana, nômade ou ciborgue. A compreensão de ser humano a partir de uma perspectiva humanista - separada dos demais elementos do mundo - mostra-se limitada na discussão referente a essas identidades consideradas dissidentes.

Braidotti (2015) ressalta que nem todos nos identificamos como pós-humanos. É importante, portanto, refletirmos sobre os caminhos necessários para desenvolver essa identidade, de modo

\footnotetext{
9 "o que nós entendemos como condições incapacitantes - social, física, mentalmente ou de outras maneiras muda ao longo do tempo e conforme o lugar, e considerar a lesão como sendo puramente física obscurece os efeitos de tais mudanças" (tradução nossa).

10 "[...] quando eu andava, [...] falavam de mim que eu caminhava como um macaco. E eu penso que, para muitas pessoas com deficiência, a violência e o tipo de ódio existe muito nesta lembrança das pessoas de que nossos corpos vão envelhecer e vão morrer. E, de diferentes formas, eu também me pergunto [...] onde nossas fronteiras nos posicionam como humanos e o que se torna não-humano. Você sabe?" (tradução nossa).
} 
que a continuidade natureza-cultura possibilite aos sujeitos a identificação com as pessoas com deficiências, socialmente vistas como não-humanas. Devemos, pois, estabelecer uma ética póshumana, que priorize a coletividade em detrimento dos interesses e das capacidades individuais, que busque o compartilhar das atividades, bem como as semelhanças entre os sujeitos, enfocando a positividade mais do que a vulnerabilidade ou as limitações (BRAIDOTTI, 2015). Uma ética, portanto, que tenha a interdependência, estabelecida nas relações, como fundamento principal.

\section{Considerações Finais}

As epistemes feministas constituem um importante campo teórico para discutirmos a inclusão da pessoa com deficiência na sociedade. Foram os questionamentos feitos por pesquisadoras feministas com deficiência que possibilitaram o desenvolvimento do modelo social de consideração das deficiências, bem como de um campo de pesquisa que intersectasse as duas áreas: os estudos feministas da deficiência (feminist disability studies). Tal entendimento também se respalda no posicionamento ético e político da ciência feminista, que, a partir de um olhar situado, pressupõe a intervenção social com vistas tanto ao combate de todas as formas de desigualdade - nesse caso, promovida por uma corponormatividade compulsória - quanto à promoção da equidade. Na medida em que teorias são tecnologias, conforme propõe de Lauretis (1994) - e, desse modo, produzem, disseminam e instalam representações -, pensar a deficiência a partir das diversas problematizações estabelecidas pelas teóricas feministas amplia o debate e fundamenta a construção de uma perspectiva de complexidade em relação aos sujeitos com deficiências. Por meio da interseccionalidade, compreendemos que a deficiência é uma das suas características, dentre tantas outras. A partir da hibridização, passamos a entender que não são apenas as pessoas com deficiências que necessitam de apoios variados (humanos ou não humanos), mas todos nós, uma vez que todos somos ciborgues - o que nos remete à busca pela interdependência como um princípio de justiça mais adequado do que a independência. Em contrapartida, a abjeção se apresenta como um desafio no estabelecimento dessa proximidade e nos coloca importantes questionamentos, sendo um deles referente ao alcance da voz desses sujeitos, nos diversos ambientes que frequentam. Ao falarmos da inclusão, quais vozes ouvimos? Qual é o espaço que possibilitamos aos sujeitos com deficiência?

Tais questionamentos adquirem relevância a partir da problematização feita por Gayatri Spivak (2010) referente ao alcance das falas dos sujeitos subalternos em uma sociedade excludente e fortemente eurocentrada. Ao tratar da subalternidade, a autora não se referiu especificamente às pessoas com deficiências, mas sua definição também as inclui, pois diz respeito aos grupos minoritários excluídos das relações de mercado, da representação política e legal, sem possibilidade nem de ascensão nem de pertencimento às classes detentoras do poder.

Os sujeitos subalternos, para Spivak (2010), têm seus discursos aprisionados pelas representações socialmente elaboradas em relação aos grupos aos quais pertencem. Ainda que falem, não são realmente ouvidos. Precisam de alguém que pertença aos estratos majoritários e intermedeie suas reivindicações junto aos demais grupos sociais, sendo os intelectuais ou pesquisadores potenciais representantes.

Por esse motivo, tais representantes precisam ter clareza de que são partes constituintes das relações de poder que silenciam os subalternizados e que, por isso, não devem substitui-los. Tendo isso em vista, é importante que o pesquisador não "fale pelo" grupo que representa, porque sua fala é também atravessada pelo discurso hegemônico, mas que possibilite ser espaço de interlocução e de visibilidade, nos quais as pessoas oprimidas possam ser afirmadas como sujeitos e ser escutadas em suas manifestações. Tal ressalva faz-se premente na medida em que nos posicionamos a partir de uma episteme que privilegia uma ciência situada, implicada com a perspectiva dos sujeitos subjugados, conforme propõe Haraway (1995).

Pensar os entrelaçamentos entre os estudos feministas e de gênero e os estudos das deficiências possibilita, pois, a elaboração de um olhar mais complexo para as questões sociais que se apresentam. Permite o desenvolvimento de uma crítica com vistas à produção de outros sentidos e, consequentemente, outras realidades, nas quais as diferenças, hoje consideradas abjetas, possam ser entendidas como mais uma possibilidade de manifestação das vidas, e não como algo que deva ser normalizado ou mesmo extirpado da sociedade. Desse modo, possibilitanos ampliar o repertório de respostas a questões como: o que pode um corpo fazer? O que, no fim, conta como vida? Quais são os limites segundo os quais você ainda conta como humano?

\section{Referências}

BAMPI, Luciana N. S., GUILHEM, Dirce; ALVES, Elioenai D. "Modelo social: uma nova abordagem para o tema deficiência". Revista Latino-Americana de Enfermagem, Ribeirão Preto, v. 18, n. 4, p. 816-823, jul-ago/2010. Disponível em: http://www.scielo.br/scielo.php?script=sci_arttext\&pid=SO 104-1 1692010000400022\&Ing=en\&nrm=iso. Acesso em: 07/04/2019. 
BRAIDOTTI, Rosi. "Diferença, diversidade e subjetividade nômade". Labrys, estudos feministas, n. 12, p. 1-16, jul./dez. 2002.

BRAIDOTTI, Rosi. "Elemental complexity and relational vitality: the relevance of nomadic thought for contemporary Science". In: GAFFNEY. Peter (Ed.). The force of the virtual: Deleuze, Science, and Philosophy. Minneapolis: University of Minnesota Press, 2010, p. 21 1-228.

BRAIDOTTI, Rosi. Lo posthumano. Barcelona: Gedisa Editorial, 2015.

BUTLER, Judith. “Corpos que pesam: sobre os limites discursivos do 'sexo'”. In: LOURO, Guacira L. (Org.). O corpo educado: pedagogias da sexualidade. Trad. de Tomaz Tadeu da Silva. 2. ed. Belo Horizonte: Autêntica, 2000, p. 151-172.

BUTLER, Judith. Problemas de gênero: feminismo e subversão da identidade. Trad. de Renato Aguiar. 9. ed. Rio de Janeiro: Civilização Brasileira, 2015.

COLLINS, Patricia H.; BILGE, Sirma. Intersectionality. Cambridge, Malden: Polity Press, 2016.

DINIZ, Débora. "Modelo social da deficiência: a crítica feminista”. Série Anis, n. 28, p. 1-8, julho, 2003.

DINIZ, Débora. O que é deficiência. São Paulo: Brasiliense, 2007.

GARLAND THOMSON, Rosemarie. "Feminist Disability Studies". Signs: Journal of Women in Culture and Society, v. 30, n. 2, p. 1557-1587, 2005.

GARLAND-THOMSON, Rosemarie. "Integrating disability, transforming feminist theory". NWSA Journal, v. 14, n. 3, p. 1-32, set. 2002 .

GARLAND-THOMSON, Rosemarie. Re-shaping, re-thinking, re-defining: Feminist Disability Studies. Washington: Center for Women Policy Studies, 2001. Disponível em: https://www.womenenabled.org/ pdfs/Garland-Thomson,Rosemarie,RedefiningFeministDisabilitiesStudiesCWPR2001 .pdf. Acesso em: $11 / 04 / 2019$.

HARAWAY, Donna J. "Manifesto ciborgue: ciência, tecnologia e feminismo-socialista no final do século XX". In: HARAWAY, Donna J.; KUNZRU, Hari; TADEU, Tomaz. Antropologia do ciborgue: as vertigens do pós-humano. Trad. de Tomaz Tadeu. 2. ed. Belo Horizonte: Autêntica Editora, 2009, p. 33-118.

HARAWAY, Donna J. "Saberes localizados: a questão da ciência para o feminismo e o privilégio da perspectiva parcial". Trad. de Mariza Corrêa. Cadernos Pagu, n. 5, p. 7-41, 1995. Disponível em: https://periodicos.sbu.unicamp.br/ojs/index.php/cadpagu/article/view/1773. Acesso em: 07/04/ 2019.

KAFER, Alison. Feminist, queer, crip. Indiana: Indiana University Press, 2013. Versão para Kindle.

KAFER, Alison. "Health Rebels: A Crip Manifesto for Social Justice". Conferência ministrada no 21st annual Shepard Symposium on Social Justice - Rebel Health: Wellness Without Borders, em 06/04/ 2017. Disponível em: https://www.youtube.com/watch?v=YqcOUD1pBKw\&t=1902s. Acesso em: 11 / 05/2017.

KUNZRU, Hari. “'Você é um ciborgue': um encontro com Donna Haraway”. In: HARAWAY, Donna J.; KUNZRU, Hari; TADEU, Tomaz. Antropologia do ciborgue: as vertigens do pós-humano. Trad. de Tomaz Tadeu. 2. ed. Belo Horizonte: Autêntica Editora, 2009, p. 17-32.

LAURETIS, Teresa de. Tecnologia do gênero. In: HOLLANDA, Heloísa Buarque de (Org.). Tendências e impasses: o feminismo como crítica da cultura. Rio de Janeiro: Rocco, 1994, p. 206-241.

LLOYD, Margaret. "Does she boil eggs? Towards a feminist model of disability". Disability, Handicap \& Society, v. 7, n. 3, p. 207-221, 1992.

MCRUER, Robert. Crip Theory: cultural signs of queerness and disability. Nova lorque: New York University Press, 2006. Versão para Kindle.

MCRUER, Robert. "McRuer on Crip Theory." Entrevista realizada por Bengt Elmén e publicada em 07/ 05/2016. Disponível em: https://www.youtube.com/watch?v=IZW6yoqINv4\&t=10s. Acesso em: 02/ 05/2017. 
MCRUER, Robert. "Tiempos Cripp: discapacidad, globalización y resistencia". Conferência magistral do VII Congreso de Ciencias, Artes y Humanidades "El cuerpo descifrado" - Cuerpos excluidos. Prácticas corporales y discriminación. 29/10/2015. Disponível em: https://www.youtube.com/ watch? $\mathrm{v}=$ Q6f-97Mz1SE\&t=4668s. Acesso em: 10/05/2017.

MELLO, Anahi G.; NUERNBERG, Adriano H. "Gênero e deficiência: interseções e perspectivas". Revista Estudos Feministas, v. 20, n. 3, p. 635-655, dez. 2012. Disponível em: http://www.scielo.br/ scielo.php?script=sci_arttext\&pid=S0104-026X2012000300003\&Ing=en\&nrm=iso. Acesso em: 07/ 04/2019.

MISKOLCI, Richard. Teoria Queer: um aprendizado pelas diferenças. Belo Horizonte: Autêntica Editora, 2016.

MORRIS, Jeanny. "Feminism and disability". Feminist Review, n. 43, p. 55-67, primavera, 1993.

NEVES, Sofia; NOGUEIRA, Conceição. "Metodologias feministas: a reflexividade ao serviço da investigação nas Ciências Sociais". Psicologia: Reflexão e Crítica, v. 18, n. 3, p. 408-412, dez. 2005.

OLIVEIRA, João Manuel de. "Os feminismos habitam espaços hifenizados: a localização e interseccionalidade dos saberes feministas". Ex aequo, n. 22, p. 25-39, 2010.

ORGANIZAÇÃO MUNDIAL DE SAÚDE. Relatório mundial sobre a deficiência. Trad. de Lexicus Serviços Lingüísticos. São Paulo: SEDPCD, 2012.

PRINS, Baukje; MEIJER, Irene C. "Como os corpos se tornam matéria: entrevista com Judith Butler". Revista Estudos Feministas, v. 10, n. 1, p. 155-167, jan. 2002. Disponível em: http://www.scielo.br/ scielo.php?script=sci_arttext\&pid=S0104-026X2002000100009\&Ing=en\&nrm=iso. Acesso em: 07/ 04/2019.

REEVE, Donna. "Cyborgs, Crippes and iCrip: reflections on the contribution of Haraway to Disability Studies". In: GOODLEY, Dan; HUGHES, Bill; DAVIS, Lennard (Orgs.). Disability and Social Theory: new developments and directions. Basingstoke: Palgrave-Macmillan, 2012, p. 91-111.

ROETS, Griet; BRAIDOTTI, Rosi. "Nomadology and subjectivity: Deleuze, Guattari and Critical Disability Studies". In: GOODLEY, Dan; HUGHES, Bill; DAVIS, Lennard (Orgs.). Disability and Social Theory: new developments and directions. Basingstoke: Palgrave-Macmillan, 2012, p. 161-178.

SARDENBERG, Cecília M. B. "Da crítica feminista à ciência a uma ciência feminista?". Labrys, estudos feministas, v. 11, jan./jun. 2007. Disponível em: http://repositorio.ufba.br/ri/handle/ri/6875. Acesso em: 07/04/2019.

SPIVAK, Gayatri C. Pode o subalterno falar? Trad. de Sandra R. G. de Almeida, Marcos P. Feitosa e André P. Feitosa. Belo Horizonte: Editora UFMG, 2010.

TAYLOR, Astra. "Judith Butler with Sunaura Taylor: interdependence. In: TAYLOR, Astra (Org.) Examined Life: Excursions with Contemporary Thinkers. Nova lorque: The New Press, 2009, p. 185-213.

Molise de Bem Magnabosco (molisebm@yahoo.com.br) é doutoranda em Psicologia na Universidade Estadual Paulista (UNESP), campus de Assis; mestra em Educação pela Universidade Federal de Mato Grosso (UFMT), campus de Rondonópolis; psicóloga, atuando na Rede Municipal de Ensino da Prefeitura Municipal de Rondonópolis-MT.

Leonardo Lemos de Souza (leonardo.lemos@unesp.br) é doutor em Educação pela Universidade Estadual de Campinas (UNICAMP) e livre docente em Psicologia pela Universidade Estadual Paulista (UNESP), campus de Assis; professor associado do Departamento de Psicologia Social e Educacional, também da Universidade Estadual Paulista (UNESP), campus de Assis. 


\section{COMO CITAR ESSE ARTIGO DE ACORDO COM AS NORMAS DA REVISTA}

MAGNABOSCO, Molise de Bem; SOUZA, Leonardo Lemos de. "Aproximações possíveis entre os estudos da deficiência e as teorias feministas e de gênero". Revista Estudos Feministas, Florianópolis, v. 27 , n. 2, e56147, 2019.

\section{CONTRIBUIÇÃO DE AUTORIA}

Molise de Bem Magnabosco: concepção e elaboração do manuscrito. Revisão e aprovação da versão final do trabalho.

Leonardo Lemos de Souza: concepção do manuscrito. Revisão e aprovação da versão final do trabalho.

\section{FINANCIAMENTO}

Afastamento para qualificação profissional, concedido pela Secretaria Municipal de Educação de Rondonópolis com publicação de parecer $n^{\circ}$ 004/2006, na página 23 do Diário Oficial DIORONDON n 3689, de 12 de abril de 2016.

O presente trabalho foi realizado com apoio da Coordenação de Aperfeiçoamento de Pessoal de Nível Superior - Brasil (CAPES) - Código de Financiamento 001

\section{CONSENTIMENTO DE USO DE IMAGEM}

Não se aplica

\section{APROVAÇÃO DE COMITÊ DE ÉTICA EM PESQUISA}

Este ensaio é parte do projeto de pesquisa de doutorado da autora Molise de Bem Magnabosco, orientado pelo autor Leonardo Lemos de Souza, registrado pelo Certificado de Apresentação para Apreciação Ética 9008301 8.3.0000.5401 e aprovado, conforme parecer n².928.797.

\section{CONFLITO DE INTERESSES}

Não há conflito de interesses identificado.

\section{LICENÇA DE USO}

Este artigo está licenciado sob a Licença Creative Commons CC-BY International. Com essa licença você pode compartilhar, adaptar, criar para qualquer fim, desde que atribua a autoria da obra.

\section{HISTÓRICO}

Recebido em 02/04/2018

Reapresentado em 20/08/2018

Aprovado em 29/08/2018

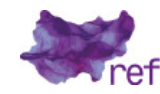

